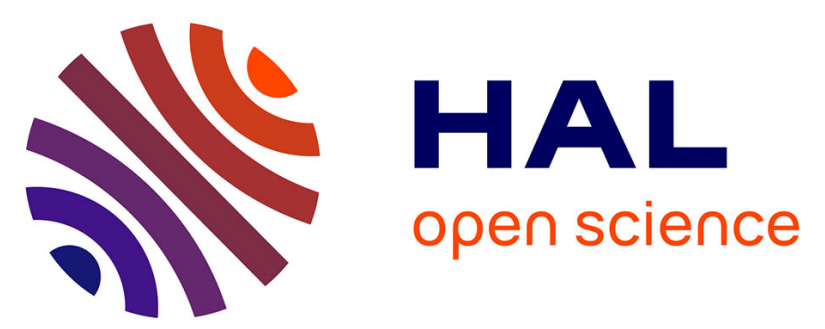

\title{
Short-term reliability of high performance Q-band AlN/GaN HEMTs
}

\author{
R. Kabouche, K. Harrouche, Etienne Okada, F Medjdoub
}

\section{To cite this version:}

R. Kabouche, K. Harrouche, Etienne Okada, F Medjdoub. Short-term reliability of high performance Q-band AlN/GaN HEMTs. IEEE International Reliability Physics Symposium (IRPS 2020), Apr 2020, Dallas, TX, United States. pp.1-6, 10.1109/IRPS45951.2020.9129322 . hal-03044147

\section{HAL Id: hal-03044147 https://hal.science/hal-03044147}

Submitted on 7 Dec 2020

HAL is a multi-disciplinary open access archive for the deposit and dissemination of scientific research documents, whether they are published or not. The documents may come from teaching and research institutions in France or abroad, or from public or private research centers.
L'archive ouverte pluridisciplinaire HAL, est destinée au dépôt et à la diffusion de documents scientifiques de niveau recherche, publiés ou non, émanant des établissements d'enseignement et de recherche français ou étrangers, des laboratoires publics ou privés. 


\title{
Short-term reliability of high performance Q-band AlN/GaN HEMTs
}

\author{
R. Kabouche ${ }^{1}$, K. Harrouche ${ }^{1}$, E. Okada ${ }^{1}$, and F. Medjdoub ${ }^{1}$ \\ ${ }^{1}$. IEMN: Institute of Electronics, Microelectronics, and Nanotechnology, CNRS, Avenue Poincare, Villeneuve d'Ascq, France
}

\begin{abstract}
We report on an on-wafer short-term $40 \mathrm{GHz}$ RF reliability stress test comparison between a $3 \mathrm{~nm}$ versus $4 \mathrm{~nm}$ barrier thickness AIN/GaN HEMT technology showing state-ofthe-art power performances in the millimeter wave range. It is found that the barrier thickness in this highly strain heterostructure has a major impact on the device reliability. The superior robustness when using thinner barrier (closer to the critical thickness) is attributed to the reduced strain.
\end{abstract}

Keywords- GaN, HEMTs, output power density (Pout), power added efficiency (PAE), Q-band, on-wafer short-term reliability

\section{INTRODUCTION}

In the last decade, considerable progress have been made in Gallium Nitride (GaN)-based RF power devices, which will enable new applications such as military wireless communication, SATCOM and $5 \mathrm{G}$ next generation of mobile broadband. Those applications operating at high frequency need compact systems, for which the power-added-efficiency (PAE) associated to a high output power density (PouT) in the millimeter-wave $(\mathrm{mmW})$ range represents currently one of the key goal for the GaN technology. Some promising data have been recently reported in this frame [1]-[3]. Nevertheless, for short $\mathrm{GaN}$ transistors delivering high performance with gate lengths below $150 \mathrm{~nm}$, the main limitation is the device reliability due to a significant electric field peak and subsequent high junction temperatures under high drain bias. That is why, very few $\mathrm{mmW} \mathrm{GaN}$ device reliability reports can be found so far in the literature.

In this work, we studied the RF robustness at $40 \mathrm{GHz}$ of two HEMT structures using $3 \mathrm{~nm}$ and $4 \mathrm{~nm}$ AlN ultrathin barriers at various temperatures.

\section{DEVICE FABRICATION AND STRESS PROCEDURE}

The two heterostructures have been grown by metal organic chemical vapor deposition (MOCVD) on 4-in. SiC substrates. They consist in an AIN nucleation layer, a 1- $\mu \mathrm{m}$ carbon-doped $\mathrm{GaN}$ buffer layer followed by an undoped $100 \mathrm{~nm} \mathrm{GaN}$ channel and a 3.0 and $4.0 \mathrm{~nm}$ ultrathin AlN barrier layer, respectively. Both HEMTs were capped with a $10 \mathrm{~nm}$ thick in-situ SiN layer used as early passivation as well as to reduce the surface trapping effects. Identical processing has been carried out on the two wafers and verified through several batches.

A short-term on-wafer RF stress has been applied at various drain bias voltage $\left(\mathrm{V}_{\mathrm{DS}}\right)$ and temperatures. $2 \times 50 \mu \mathrm{m}$ transistors with a gate-drain distance (GD) of $1.5 \mu \mathrm{m}$ and a gate length $\left(\mathrm{L}_{\mathrm{G}}\right)$ of $110 \mathrm{~nm}$ have been monitored during 24 hours by steps of 8 hours under large signal conditions at $40 \mathrm{GHz}$ at the peak PAE. Details of the power bench used for these measurements can be found in [4].

\section{DATA/RESULTS AND DISCUSSION}

Figure 1 shows the RF monitoring performed at $40 \mathrm{GHz}$ on the $4 \mathrm{~nm}$ AlN barrier structure described earlier. The devices have been tested during 24 hours at room temperature with $V_{D S}$
$=12 \mathrm{~V}$. We observed a systematic strong degradation of performances over time. The PAE decreases from $45 \%$ down to $30 \%$ after 24 hours stress while $\mathrm{P}_{\text {OUT }}$ drops from $1.4 \mathrm{~W} / \mathrm{mm}$ down to $0.8 \mathrm{~W} / \mathrm{mm}$. The same test has been attempted at higher $\mathrm{V}_{\mathrm{DS}}$. After few minutes at $\mathrm{V}_{\mathrm{DS}}=15 \mathrm{~V}$ and $20 \mathrm{~V}$, the devices deliver significant gate leakage current as shown in Figure 2.

On the other hand, the $3 \mathrm{~nm}$ AlN barrier devices show no degradation when subjected to the same RF stress at $40 \mathrm{GHz}$ at room temperature during 24 hours with $\mathrm{V}_{\mathrm{DS}}=20 \mathrm{~V}$ (Fig. 3 and 4) and $V_{D S}=30 \mathrm{~V}$ (Fig. 7 and 8). For this $110 \mathrm{~nm}$ technology, the PAE (50\%) with a Pout around $3 \mathrm{~W} / \mathrm{mm}$ at $40 \mathrm{GHz}$ remains stable with no increase of gate and drain leakage currents up to $\mathrm{V}_{\mathrm{DS}}=30 \mathrm{~V}$.

The high robustness has been verified at higher temperature. Thus, the base-plate temperature $\left(T_{b p}\right)$ has been increased up to $140^{\circ} \mathrm{C}$ by steps of 4 hours while using identical RF stress conditions at $40 \mathrm{GHz}$. The estimated junction temperature in this case is well-above $250^{\circ} \mathrm{C}$. Figure 5 shows a slight reduction of the PAE as a function of temperature from $47 \%$ at $\mathrm{T}_{\mathrm{bp}}=50^{\circ} \mathrm{C}$ down to $40 \%$ at $\mathrm{T}_{\mathrm{bp}}=140^{\circ} \mathrm{C}$. This decrease is due to the thermal impact on the electron mobility, which affects the gain and thus the PAE. Owing to a compensation of the gate bias voltage at every $\mathrm{T}_{\mathrm{bp}}$ to fix and maintain the drain current at $100 \mathrm{~mA} / \mathrm{mm}$, Pout remains stable. It can be noticed that for each temperature, the PAE is stable during the 4 hours stress. Furthermore, after the entire test of 24 hours at several temperatures, the degradation observed on the PAE is fully reversible and recovers to its initial value. It is also important to note that no leakage current is observed with an off-state current below 100 $\mu \mathrm{A} / \mathrm{mm}$ (see Fig. 6). The superior robustness combined with outstanding $\mathrm{mmW}$ performance are attributed to the reduction of the barrier thickness. It is believed that the improvement is directly related to the reduced strain when decreasing the barrier thickness. Further investigations will be carried out in order to confirm this assumption.

\section{CONCLUSIONS}

In this work, two heterostructures for $\mathrm{mmW}$ applications based on AlN/GaN material with $3 \mathrm{~nm}$ and $4 \mathrm{~nm}$ barrier thickness have been compared in terms of device robustness for 24 hours. The $4 \mathrm{~nm}$ AlN barrier devices show a strong RF performance degradation at room temperature at $\mathrm{V}_{\mathrm{DS}}=12 \mathrm{~V}$ and a full degradation for higher $\mathrm{V}_{\mathrm{DS}}$. However, no degradation is observed up to $\mathrm{V}_{\mathrm{DS}}$ as high as $30 \mathrm{~V}$ and $\mathrm{T}_{\mathrm{bp}}=140^{\circ} \mathrm{C}$ during 24 hours for the $3 \mathrm{~nm}$ AlN barrier devices. This is attributed to the strain reduction when using thinner barrier thickness. These results pave the way for highly reliable high performance $\mathrm{mmW}$ $\mathrm{GaN}$ transistors.

\section{REFERENCES}

[1] B. Romanczyk et al., Int. Electron Device Meet., pp. 67-70, 2016

[2] E. Dogmus et al, Phys. Status Solidi a, vol. 1, pp. 1-4. 2017.

[3] D. F. Brown et al., IEEE Int. Electron Device Meet., pp. 461-464, 2011.

[4] R. Kabouche et al, IEEE Microw. Wirel. Components Lett., vol. 27, no. 4, pp. 419-421, 2017 


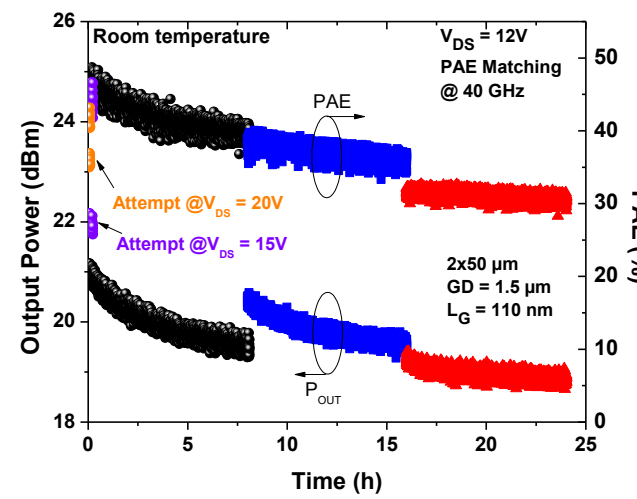

Figure 1. Output power and PAE monitoring for 24 hours at room temperature with $V_{D S}=12,15$ and $20 \mathrm{~V}$ (PAE matching).

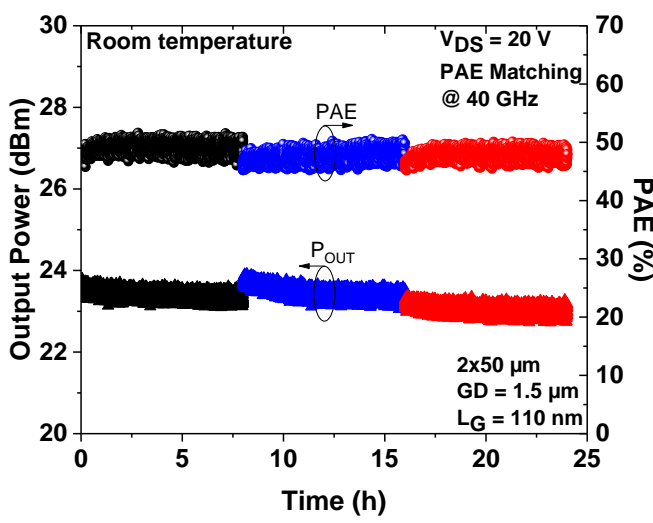

Figure 3. Output power and PAE monitoring for 24 hours at room temperature with $V_{D S}=20 \mathrm{~V}$ (PAE matching).

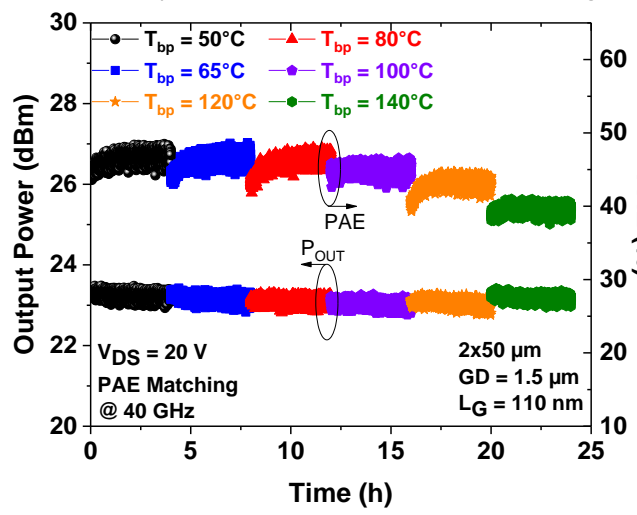

Figure 5. Output power and PAE monitoring for 24 hours for several temperatures upt ot $140^{\circ} \mathrm{C}$ with $V_{D S}=20 \mathrm{~V}$ (PAE matching).

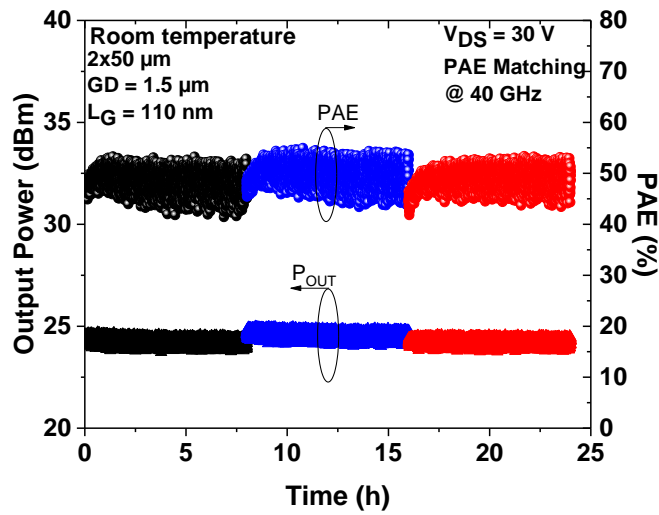

Figure 7. Output power and PAE monitoring for 24 hours at room temperature with $V_{D S}=30 \mathrm{~V}$ (PAE matching).

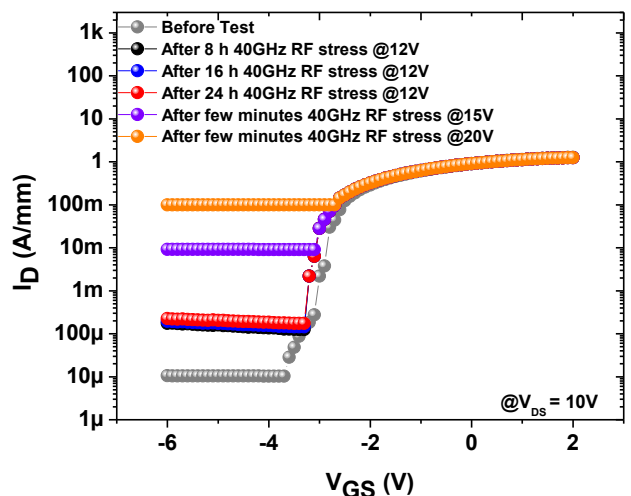

Figure 2. Transfer characteristics before and after 8,16 and 24 hours of $40 \mathrm{GHz} R F$ stress at $V_{D S}=12,15$ and $20 \mathrm{~V}$ at room temperature.

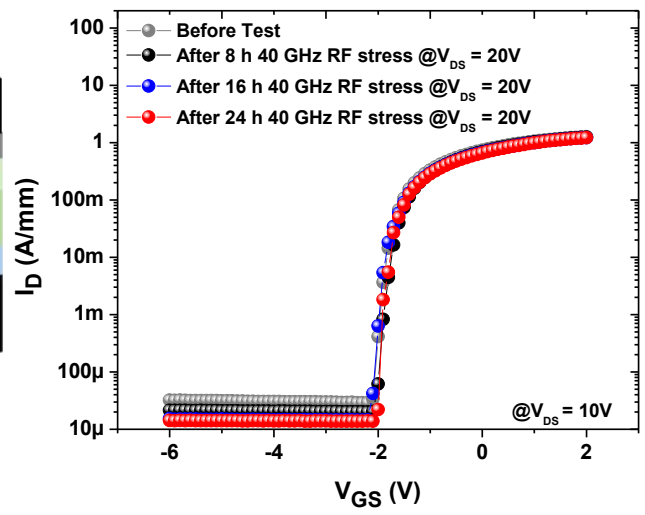

Figure 4. Transfer characteristics before and after 8,16 and 24 hours of $40 \mathrm{GHz} R F$ stress at $V_{D S}=20 \mathrm{~V}$ at room temperature.

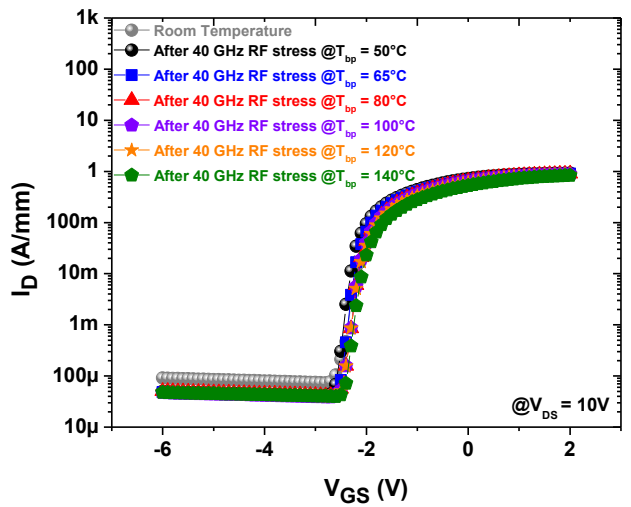

Figure 6. Transfer characteristics before and after 4 hours at 50,65, 80, 100, 120 and $140^{\circ} \mathrm{C}$ of $40 \mathrm{GHz}$ RF stress at $V_{D S}=20 \mathrm{~V}$.

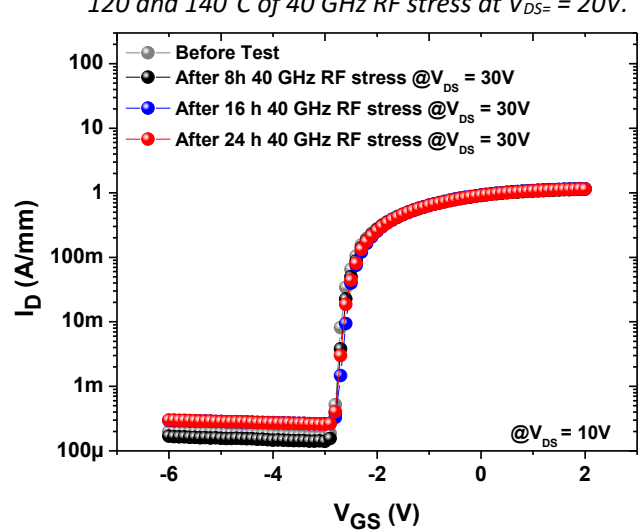

Figure 8. Transfer characteristics before and after 8, 16 and 24 hours of $40 \mathrm{GHz} R \mathrm{~F}$ stress at $V_{D S}=30 \mathrm{~V}$ at room temperature. 